OPEN ACCESS

Edited by:

Ling-Qing Yuan,

Central South University, China

Reviewed by:

Aileen King,

King's College London,

United Kingdom

Andrew R. Pepper,

University of Alberta, Canada

Alexandra Smink,

University Medical Center Groningen,

Netherlands

*Correspondence: Yong Zhao

Yong.Zhao@ThroneBio.com

${ }^{\dagger}$ These authors have contributed equally to this work

Specialty section: This article was submitted to Translational Endocrinology, a section of the journal

Frontiers in Endocrinology

Received: 17 March 2021 Accepted: 06 December 2021

Published: 12 January 2022

Citation:

Hu W, Song $X, Y u H$, Sun J, Wang $H$ and Zhao $Y$ (2022)

Clinical Translational Potentials of

Stem Cell-Derived Extracellular

Vesicles in Type 1 Diabetes.

Front. Endocrinol. 12:682145. doi: 10.3389/fendo.2021.682145

\section{Clinical Translational Potentials of Stem Cell-Derived Extracellular Vesicles in Type 1 Diabetes}

\author{
Wei $\mathrm{Hu}^{1+}$, Xiang Song ${ }^{1+}$, Haibo $\mathrm{Yu}^{1}$, Jingyu Sun ${ }^{2}$, Hongjun Wang $^{2}$ and Yong Zhao ${ }^{1,3 *}$ \\ ${ }^{1}$ Center for Discovery and Innovation, Hackensack Meridian Health, Nutley, NJ, United States, ${ }^{2}$ Department of Chemistry \\ and Chemistry Biology, Stevens Institute of Technology, Hoboken, NJ, United States, ${ }^{3}$ Throne Biotechnologies Inc., \\ Paramus, NJ, United States
}

Type 1 diabetes (T1D) is an organ-specific disease characterized by the deficiency of insulin caused by the autoimmune destruction of pancreatic islet $\beta$ cells. Stem cell-based therapies play essential roles in immunomodulation and tissue regeneration, both of which hold great promise for treating many autoimmune dysfunctions. However, their clinical translational potential has been limited by ethical issues and cell transplant rejections. Exosomes are small extracellular vesicles (EVs) released by almost all types of cells, performing a variety of cell functions through the delivery of their molecular contents such as proteins, DNAs, and RNAs. Increasing evidence suggests that stem cell-derived EVs exhibit similar functions as their parent cells, which may represent novel therapeutic agents for the treatment of autoimmune diseases including T1D. In this review, we summarize the current research progresses of stem cell-derived EVs for the treatment of T1D.

Keywords: extracellular vesicle, stem cell, type 1 diabetes, exosome, autoimmunity, immunomodulation, $\beta$-cell regeneration

\section{INTRODUCTION}

Type 1 diabetes (T1D) is an autoimmune disorder characterized by impaired blood sugar control and insulin deficiency due to an autoimmune destruction of insulin-producing cells in the pancreas (1). Long-term hyperglycemia increases the risks of developing a number of diabetes-associated complications such as cardiovascular disease, kidney diseases, stroke, and blindness. These complications lead to a significant reduction in the quality of life for those affected (2). While the exact pathogenesis of T1D remains unknown, it is associated with a combination of environmental factors and genetic predisposition (3). The administration of exogenous insulin only alleviates symptoms and cannot fully mimic the physiological actions of endogenous insulin released from healthy pancreata. Pancreatic islet transplantation has become a potential treatment for T1D; however, drawbacks impeding its widespread application include high costs, a shortage of islet donations, and lifelong utilizations of immune-suppression drugs post-transplantation $(4,5)$. Recently, functional insulin-producing cells have been generated from embryonic stem cells (ESC) and induced pluripotent stem cells (iPSCs) (6-8). This has led to clinical trials for the treatment of T1D subjects including ViaCyte studies with VC-01 and VC-02 products (NCT04678557 and NCT03163511, respectively) and a Vertex study with VX-880 (NCT04786262). 
Clinical applications of stem cell-derived insulin-producing cells may have ethical and safety concerns including potential tumor formations and immunological reactions (9). Therefore, understanding how to correct autoimmunity and overcome the deficiency of islet $\beta$ cells are two critical concerns for the treatment of T1D.

Extracellular vesicles (EVs) are groups of small membranous particles that are released by various cells and play an essential role in the transfer of information between adjacent and distant cells (10), as well as the mediation of numerous physiological and pathophysiological processes (11). Since EVs have been found in all mammal biofluids, EVs containing biomolecules (RNAs and proteins) have been widely applied as biomarkers for diagnosis of diseases (12). Notably, increasing evidence has demonstrated the therapeutic potentials of EVs in various diseases including cancer, autoimmune diseases, and infection diseases $(13,14)$. To date, increasing evidence has demonstrated that stem cellderived EVs with similar functions as their parent cells not only contribute to the promotion of tissue regenerations (15) but also the modulation of various functions of immune cells (16) and amelioration of autoimmunity in islets $(17,18)$. This review will focus on current advancements of stem cell-derived EVs for the treatment of T1D with a special focus on their immune modulations and therapeutic potentials to overcome the deficit of islet $\beta$ cells.

\section{EXTRACELLULAR VESICLES}

\section{EV Biogenesis and Isolation}

EVs are divided into three categories according to their subcellular origin and secretion mechanisms: exosomes (30-150 nm), microvesicles (MVs, 100-1,000 nm), and apoptotic bodies (1,000-5,000 nm) (19). MVs, also termed "microparticles", are generated through direct budding at the plasma membrane. Apoptotic bodies are relatively large particles, with sizes ranging from 500 to $2,000 \mathrm{~nm}$ in diameter and derived from the late stage of apoptotic cells $(19,20)$. Exosomes, the smallest vesicles, are derived from endosomal budding and released into the lumen through exocytosis $(21,22)$. To explore the physiological and therapeutic functions of exosomes, the purification and quantification of exosomes are necessary to meet the requests of basic science and clinical practice. Several methods have been utilized to facilitate the isolation of EVs including precipitations, immune-affinity capture, ultracentrifugation (UC), sucrose density gradient ultracentrifugation, and size exclusion chromatography (SEC) (23). Each method is based on one particular feature of EVs, such as density, size, and surfacespecific proteins. These methods have certain limitations in the purity and low yield of exosomes (24). Among these techniques, ultracentrifugation is the "gold" standard and is widely accepted for EVs experimental research (25). Recently, the microfluidicsbased method has advanced exosome isolation with the high purity and high yield of exosomes (26). In the field of EVs, most studies have focus on the exosomes. Due to the overlapping range of size and density, as well as lack of specific protein markers for these three subtype EVs, the purification of separated exosomes, MVs, and apoptotic bodies is technically complicated. In this review, we use the term "EVs" on behalf of exosomes and MVs, and apoptotic bodies.

\section{Composition of EVs}

The membrane of EVs consisting of lipid bilayer is similar to that of cell plasma membrane and is in contrast with the singlelayered high-density lipoprotein (HDL) and low-density lipoprotein (LDL) found in body fluids (27). Molecular characteristics revealed that there are a variety of biomolecules such as RNAs, DNA, proteins, and lipids inside EVs. Exosomes from different sources contain certain source-specific molecules, as well as common molecules found across all types of exosomes. Exosomes manufactured from the endocytic pathway inherit endosomal components such as Alix and Tsg101 molecules. Other molecules, including tetraspanin (CD9, CD63, and CD81), membrane molecules (integrins), and intercellular adhesion molecule 1 (ICAM-1), and cytoskeletal components (tubulin, actin, and annexins) are universally presented in almost all types of exosomes derived from different sources of cellular $(28,29)$. Microvesicle cargo was dependent on the cellular source since the formation of MVs was directly generated from outward budding of cell plasma membrane, along with cytosolic and plasma membrane-associated proteins (30). Several proteins commonly identified in MVs include tetraspanins, cytoskeletal proteins, heat shock proteins, and integrins (31). However, there were no EV-specific markers to distinguish MVs from exosomes. The compositions of apoptotic bodies were different among exosomes and MVs, in that they contain the degraded protein, DNA fragments, or even intact organelles (32). Therefore, recent studies showed that native EVs carry biological cargo from different cells acting as novel mediators. They may contribute to intercellular communications and modulate the recipient cells' function and demonstrate how EVs serve as biomarkers and therapeutic agents for both diagnosis and treatment among various diseases $(33,34)$.

\section{THERAPEUTIC POTENTIALS OF STEM CELL-DERIVED EXOSOMES FOR THE CORRECTION OF MULTIPLE IMMUNE DYSFUNCTIONS IN T1D}

Stem cell-derived EVs display great potential in immune modulation, which may be translated into clinical treatment of T1D. The released EVs enter into circulation and target different cells via direct fusion with plasma membrane, endocytosis by phagocytosis, or receptor-ligand interaction (35). Immediately, after EV's molecular content (miRNAs and proteins) is released into these targeted cells, contributing to the immunomodulation through different signaling pathways $(36,37)$. In the following section, we review current advancements for the modulation of stem cell-derived EVs on different immune cell compartments as alternative approach to correct the immune dysfunctions in T1D (Figure 1). 


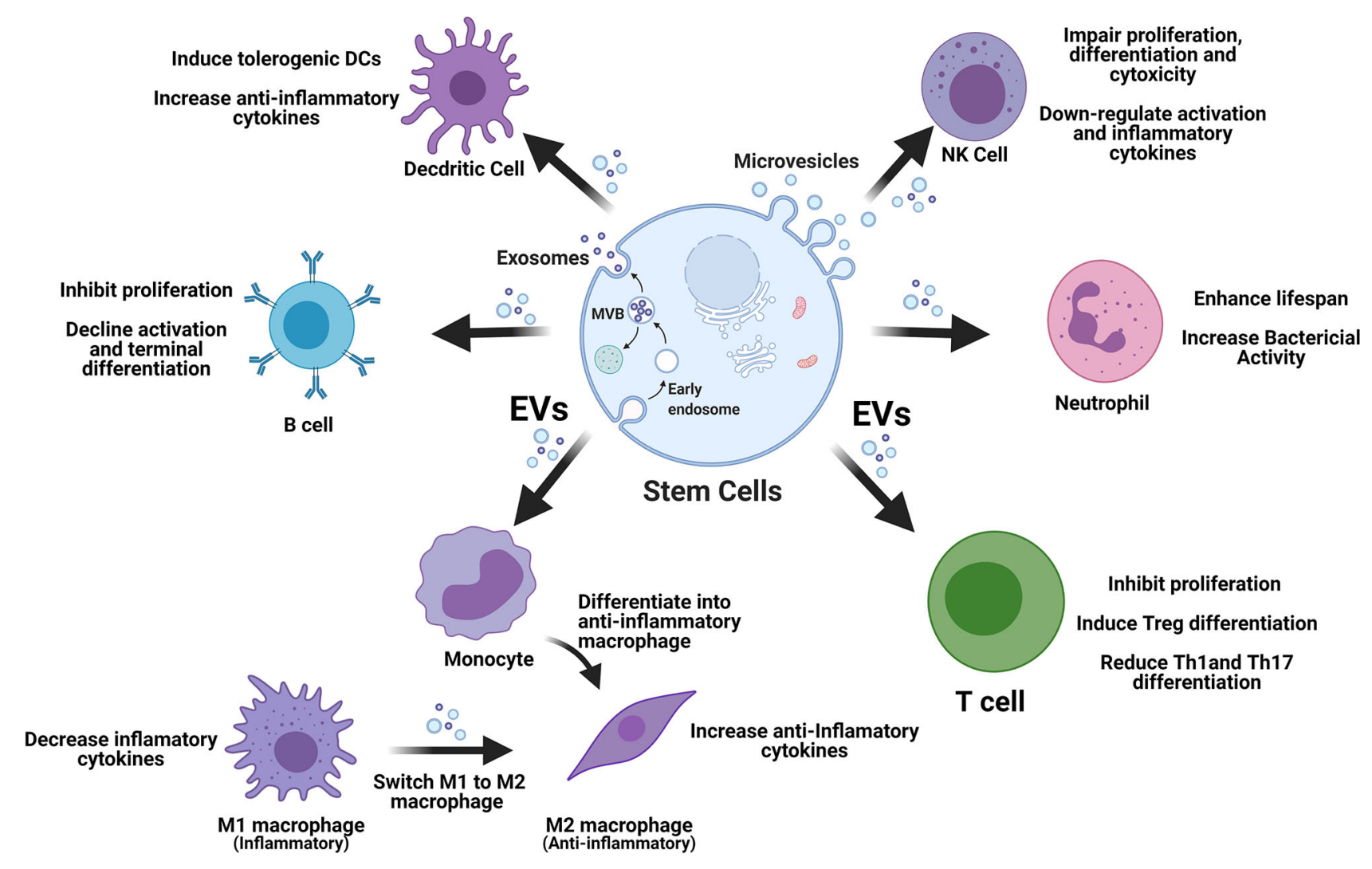

FIGURE 1 | Stem cell-derived EVs display multiple immune regulations on different types of immune cells. EVs, extracellular vesicles; M1, type 1 macrophages; M2, type 2 macrophages; NK, natural killer cells; Tregs, regulatory T cells.

\section{Immune Modulation of Stem Cell-Derived EVs on T Cells}

$\mathrm{T}$ cells as pathogenic effector cells in type 1 diabetes are well established. Both CD4+ and CD8+ cells play distinct and highly pathogenic roles driving diabetogenesis. CD8 $+\mathrm{T}$ cells are the predominant and inflammatory T-cell population contributing to the destruction of pancreatic islet $\beta$ cells. Wiedeman et al. found that the rapid loss of C-peptides in T1D subjects is associated with prevalent islet-specific $\mathrm{CD} 8+$ memory $\mathrm{T}$ cells (38). CD8+ T cells predominantly infiltrate the islets, yet their activations are primed by CD4+ T cells (39). For example, diabetogenic CD8+ T-cell functions are maintained by CD4+ $\mathrm{T}$ cells in diabetic pancreata (40). CD4+ T cells can give rise to different functional subsets in response to different signals, offering to "help" effector immune cells in their immune response (41). Increasing evidence has demonstrated that multiple $\mathrm{CD} 4+\mathrm{T}$ cells are involved in the development of insulitis, including T-helpers type 1, 2, and 17 (Th1, Th2, and Th17), regulatory $\mathrm{T}$ cells (Treg), and follicular $\mathrm{B}$ helper $\mathrm{T}$ cells (Tfh) (42-44). Studies have revealed an altered balance between Th1/Th17 and Th2 immune responses leading to T1D $(45,46)$. Tregs are critical regulators of peripheral tolerance, with defects in Treg phenotypes and suppressive capacities being reported in T1D patients (47-49). Tfh cells regulate germinal center (GC) formation and humoral response (50). Recently, studies have found that long-lived plasma cells secrete T1D-associated autoantibodies generated from GCs with the help of Tfh cells (51).

Stem cells with strong immune modulations have been applied to correct the dysfunction of T cells in T1D diabetes. Researchers found that both $\mathrm{CD} 4+$ and $\mathrm{CD} 8+$ regulatory $\mathrm{T}$ cells increase after coculturing with MSC. Fiorina et al. claim that allogeneic MSC administration can shift the Th1/Th2 balance among T1D mice models (52). Furthermore, several studies have reported that MSC could induce Treg differentiation and restore the balance between Th1/Th17s and Tregs through ex vivo and animal tests $(53,54)$. Moreover, cord blood-derived stem cells (CB-SC), with the effective immune modulation function, have been applied in the Stem Cell Educator ${ }^{\circledR}$ therapy for the treatment of T1D and autoimmune diseases. The attached CB-SC coculture with patient's apheresis mononuclear cells (MNC) for a short period (8-17 h). Consequently, the CB-S-educated MNC cells are returned back into the patient's blood circulation through infusion (55). Our previous clinical studies have demonstrated that Stem Cell Educator therapy utilizing cord blood-derived stem cells (CB-SC) can increase Th2-related cytokines (IL-4 and IL-12), decrease the level of Th17-associated cytokine (IL-17) (55), and reduce the percentages of $\mathrm{CD} 4+$ and $\mathrm{CD} 8+$ effector memory $\mathrm{T}$ 
cells $\left(\mathrm{T}_{\mathrm{EM}}\right)$ in T1D patients (56). Additionally, mechanistic studies have demonstrated the direct downregulation of the anti-CD3/ CD28 bead-activated CD4+HLA-DR+ and CD8+HLA-DR+ T cells after the treatment with CB-SC-derived exosomes (57).

Stem cell-derived EVs display similar characterization as their parent cells and play an essential role in modulations of the Tcell proliferation, differentiation, and apoptosis $(58,59)$. It has been reported that stem cell-derived EVs inhibit the proliferation of $\mathrm{T}$ cells through the delivery of their specific protein or miRNAs (60). Stem cell-derived EVs could increase the percentage of Tregs and decrease Th1/Th17 subpopulations (61), highlighting the therapeutic potential of stem cell-derived EVs for the treatment of T1D. Recently, Shigemoto-Kuroda et al. found that human MSC-derived EVs can effectively prevent the onset of T1D in animal models. Using the mixed lymphocyte reaction (MLR) assays, these MSC-EVs are able to suppress the proliferation of Th1 and Th17 cells, which play a key role in the prevention of T1D onset (62). Similarly, Favaro et al. found that MSC-derived EVs can decrease the number of Th17 cells and cytokine IL-17, as well as increase the percentage of Tregs in peripheral blood mononuclear cells (PBMC) from recent-onset T1D patients (63). Additionally, this group found that MSC-EVs could decrease the level of IFN- $\gamma$ in GAD65-stimulated PBMC and increase the level of anti-inflammation molecules, including the transforming growth factor- $\beta$ (TGF- $\beta$ ), IL-10, and prostaglandin E2 (PGE-2) (64). Stem cell-derived EVs therefore have significant importance for T1D therapy. Nojedehi et al. applied EVs from adipose tissue-derived MSC (50 $\mu \mathrm{g} / \mathrm{ml}$ in PBS, i.p., twice/week/mouse) for the treatment of chemical streptozotocin (STZ)-induced diabetic mice. Their study found that MSC-EVs are helpful in maintaining blood glucose and body weight. What is more, a mechanistic study revealed that there were significant upregulations in the levels of IL-4, IL-10, and TGF- $\beta$, as well as markedly decreased levels of IFN- $\gamma$ and IL-17 among T1D mice after the treatment with MSCderived EVs (65). Collectively, these data indicate the therapeutic potentials of stem cell-derived EVs as a novel approach to treating T1D through their immune modulations on T cells.

\section{Immune Modulation of Stem Cell-derived EVs on the Antigen-Presenting Cells}

Macrophages, one of the major antigen-presenting cells, have vital roles in the innate immune responses, glucose and lipid metabolism, and pathogenesis of diabetes $(66,67)$. Macrophages can be simplified into two subsets-pro-inflammatory (M1) and anti-inflammatory (M2) profiles (68). M1 macrophages are induced by Th1-related cytokines (IFN- $\gamma$ and TNF- $\alpha$ ) or microbial products [Toll-like receptors (TLRs), ligands, and lipopolysaccharide (LPS)] to kill pathogens and present their antigens to $\mathrm{T}$ cells for adaptive responses. M1 macrophages exhibit high levels of phagocytic activity and enhanced antigen-presenting capability through the expression of M1associated markers including CD80, CD86, and nitric oxide synthase (iNOS). Additionally, M1 macrophages produce high levels of proinflammatory cytokines such as interleukin-12 (IL12), IL-1 $\beta$, and IL-23. In contrast, M2 macrophages are induced by Th2-response cytokines (IL-4 and IL-13). M2 macrophages are characterized by an anti-inflammatory profile that plays a crucial role in permitting the resolution of tissue repair $(69,70)$ and secrete a variety of anti-inflammatory mediators (e.g., IL-10 and TGF- $\beta 1$ ) and reduce the level of proinflammatory cytokines secreted by M1 macrophages (71). In addition, M2-associated markers include CD163, mannose receptor (CD206), STAT6, and arginase $1(72,73)$. M2 macrophages with high expressions of arginase result in the production of polyamines and collagen, both of which favor tissue remodeling (74). Moreover, M2 macrophages with increased activity of arginase-1 can lower the level of NO secretion by competing for L-arginine, the substrate of iNOS (75). Both macrophages are essential players in the pathogenesis of T1D. While M1 macrophages trigger the immune response and initiate insulitis, M2 macrophages act as negative regulators by decreasing inflammation and insulitis in the T1D pancreas (70).

Macrophages may directly provoke or enhance insulin secretion through the production of factors such as retinoic acid (76). The depletion of islet-resident macrophages limits the islet leukocytic infiltration during early phases of diabetogenesis $(77,78)$. Both macrophage populations are central players in diabetes. M1 macrophages are responsible for triggering the inflammatory response, initiating insulitis and pancreatic cell death during the onset of T1D. M2 macrophages decrease hyperglycemia, insulitis, and inflammation in the pancreas, thereby negatively regulating T1D development (70). Fernando et al. found that LPS restimulation in diabetic bone marrow-derived macrophages (BMDM) resulted in higher secretions of TNF- $\alpha$ compared to non-diabetic BMDM (79). What is more, their study found that long-term high glucose-treated macrophages increased the levels of inflammatory cytokines (e.g., IL-1 $\beta$ and TNF- $\alpha$ ) in macrophages (80). Similarly, Ferris et al. reported that an increased inflammatory signature in islet macrophages of nonobese diabetic (NOD) mice was correlated with the elevated expressions of chemokines and oxidative responses (81).

Increasing evidence has demonstrated that stem cell-derived EVs can reduce the inflammation through targeting macrophages $(82,83)$. Stem cell-derived EVs can both promote M2 macrophages and suppress M1 macrophage polarization by upregulating anti-inflammation cytokines and downregulating inflammation-related cytokines $(84,85)$. Interestingly, researchers have reported that MSC exosome-treated macrophages can reduce the inflammation and $\mathrm{T}$-cell proliferation $(86,87)$. Recently, our studies demonstrated that CB-SC-derived exosomes can favorably target monocytes in the presence of PBMC and polarize these monocytes into M2 macrophages $(57,88)$. These functions may contribute to the clinical therapeutic potentials of Stem Cell Educator therapy to treat T1D (55) and other inflammatory-associated diseases (89).

Dendritic cells (DC) are another major population of antigenpresenting cells. Recent studies suggest that diabetic subjects have impaired functions of DC that may contribute to the pathogenesis of T1D $(90,91)$. Their findings revealed that adenosine deaminase (ADA) is upregulated in NOD dendritic 
cells, which induce their spontaneous activation. Therefore, transferring the ADA-deficient DC to NOD mice can protect them from the development of diabetes (92). MSCs have been shown to inhibit the maturation and function of bone marrowderived DC (BMDC) and induce the differentiation of DC into tolerogenic dendritic cells (93, 94). Similarly, MSC-derived exosomes suppress the maturation of BMDC with decreased secretion of pro-inflammatory cytokines (IL-12) and increase the production of anti-inflammatory cytokines (TGF- $\beta$ ), contributing to the DC-induced immune responses $(95,96)$. Mechanistic studies have demonstrated that MSC-derived exosomal miRNA-146a play an essential role in the immunomodulatory function of DC (97). Furthermore, Favaro et al. reported that the treatment of DC with MSC-derived EVs can increase the percentage of Tregs and decrease Th17, thus potentially leading to the inhibition of inflammatory $\mathrm{T}$-cell response to islet antigens (63).

\section{Immune Modulation of Stem Cell-Derived EVs in Other Immune Cells}

In addition to $\mathrm{T}$ cells and monocytes/macrophages involved in the initiation of $\mathrm{T} 1 \mathrm{D}$, other immune cells contribute to the development of T1D $(98,99)$. Natural killer (NK) cells may be involved in the pathophysiology of diabetes since they partner with antigen-presenting cells or $\mathrm{T}$ cells for killing the targeted islet $\beta$ cells (100). Literature has demonstrated that NK cells also release cytokines that transmit adaptive immunity. In vitro studies have confirmed that NK cells can lyse islet cells (101). Animal studies have demonstrated that the depletion of NK cells can significantly decrease T1D development (102). Stem cells can interact with NK cells for modulating these NK functions (103). For example, MSCs can inhibit IL-2-inuduced NK cell proliferation and downregulate expressions of activating NK receptors (104). Recently, MSC-derived exosomes were shown to reduce the release of interferon gamma (IFN- $\gamma$ ) and tumor necrosis factor alpha (TNF- $\alpha$ ) by activated NK cells, alleviating the inflammatory response (105). Moreover, Fan and colleagues reported that human fetal liver MSC-derived exosomes impair NK proliferation, differentiation, and cytotoxicity through exosome-associated TGF- $\beta$ (106).

$B$ cells have an important role in the adaptive immune response including antibody production, antigen presenting, and multiple cytokine production $(107,108)$. Although there is much evidence that $\mathrm{T}$ cells play a major pathogenic role in T1D, B cells are also required for the development of diabetes, which has been demonstrated by the depletion of B cells using anti-CD20 or antiCD22 monoclonal antibodies (mAb) $(109,110)$. Additionally, depleting B cells with anti-CD20 mAb in patients with newly diagnosed T1D can preserve islet $\beta$-cell function and delay the requirement for insulin administration among 1-year follow-ups $(111,112)$. Stem cells have proven immunomodulatory properties for both the activation and proliferation of $\mathrm{B}$ cells as well as the induction of regulatory B-cell generation $(113,114)$. MSC-derived EVs can affect the mRNA expression of B cells and impair their proliferation (115). Adamo et al. reported that MSC-derived exosomes can inhibit the proliferation and activation of B cells by downregulating their PI3K-AKT signaling pathway through the delivery of exosomal miR-155-5p (116).

Neutrophils are the primary innate cells to be recruited to the sites of inflammation, as they provide the front line of defense against the infection. Neutrophil functions have been reported to be closely related to $\beta$-cell autoimmunity, as a significant decrease in neutrophil numbers and chemotactic activity can be detected in T1D patients, but not among the healthy controls $(117,118)$. Additionally, the impaired phagocytosis and bactericidal activity of neutrophils were shown in marked correlation with the elevated blood glucose levels (119). There is more evidence demonstrating that treatment with stem cells can enhance the lifespan and bactericidal activity of neutrophils (120-122). Interestingly, since EVs have similar functioning as their parent cells, stem cell-derived EVs could significantly prolong the survival and function of neutrophils $(123,124)$.

\section{THERAPEUTIC POTENTIALS OF STEM CELL-DERIVED EVS FOR OVERCOMING THE SHORTAGE OF ISLET BETA CELLS IN T1D}

Pancreatic $\beta$ cells are the only specialized cells in mammals that can secrete insulin. Cytoarchitectural studies in rodents have shown that they are located in the core of the rodent pancreatic islets and are surrounded by $\alpha$ cells, which can secrete glucagon, $\delta$ cells, which are few in number and secrete somatostatin, and PP cells, which secrete pancreatic polypeptide (125). Conversely, human islet $\beta$ cells, $\alpha$ cells, and $\delta$ cells were found scattered through the human islets (126). The destruction of pancreatic $\beta$ cells results in absolute insulin secretion deficiency-the hallmark characteristic of T1D (127). Understanding how to restore the islet $\beta$-cell population is one of the most challenging fields in the treatment of T1D. Nevertheless, a number of hurdles must be overcome. Currently, several known approaches have been applied to $\beta$-cell regeneration including endogenous regeneration of $\beta$ cells, in vitro $\beta$-cell regeneration using stem cells, and the promotion of the remaining $\beta$ cells that have survived $(128,129)$. Stem cells have great differentiation potential, being able to differentiate into endogenous $\beta$ cells or in vitro insulin-producing cells. In addition, stem cells have powerful modulation functions for promoting the survival of remaining $\beta$ cells $(130,131)$. Recently, more evidence has suggested that stem cell-derived EVs have positive effects for promoting the survival of $\beta$ cells and generation of insulinproducing cells $(132,133)$.

\section{Effects of Stem Cell-Derived EVs on Endogenous $\beta$-Cell Proliferation and Transdifferentiation}

Endogenous regeneration of $\beta$ cells, which occurs through the stimulation of existing $\beta$-cell proliferation or differentiation of other pancreatic progenitor cells or stem cells into functional insulin-secreting cells (designated neogenesis), is a potential 
strategy for residual $\beta$-cell replication and neogenesis to treat diabetes (134). Pancreatic $\beta$-cell replication occurs readily during the fetal and neonatal stages and then declines after these stages. Increasing evidence has demonstrated that several mitogenic signaling pathways mediate the replication of $\beta$ cells including IRS-PI3K-AKT, GSK3,cMYC, RAS/RAF/ERK, and mTOR (135). Interestingly, insulin signaling can regulate the mitotic FoxM1/ PLK1/CENP-A pathway for promoting adaptive $\beta$-cell proliferation (136). In addition, multiple soluble factors, including GLP-1, lepin, and IL-6, have been implicated to control the proliferation of $\beta$ cells. For example, studies have demonstrated that the transforming growth factor (TGF)-beta family and WNT/beta-Catenin signaling serve as the potential keys to controlling $\beta$-cell proliferation and differentiation (137139). Moreover, increasing evidence has demonstrated that stem cell infusions can enhance the cell proliferation during the process of tissue repair $(140,141)$. Recently, scientists have applied human MSC with overexpressions of telomerase reverse transcriptase (TERT) to enhance the proliferation of autochthonous pancreatic $\beta$ cells in half-pancreatectomized mice (142). Also, stem cell-derived EVs cause positive effects for the treatment of T1D by promoting existing $\beta$-cell proliferation. For instance, Mahdipour et al. found that applying EVs from menstrual blood-derived MSCs $(10 \mu \mathrm{g} / \mathrm{rat}$, i.v., on day 0,2 , and 10 after the injection of streptozotocin, respectively) can restore the $\beta$-cell mass and insulin production in diabetic rats. Mechanistic studies have revealed that EVs can induce $\beta$-cell regeneration through the activation of the pancreatic and duodenal homeobox 1 (PDX-1) pathways (143). Additionally, the reprogramming of cells into $\beta$-like cells has drawn increasing attention among the research community as an alternative means for endogenous $\beta$-cell regeneration. According to the development of embryonic pancreatic $\beta$ cells, transcription factors play an essential role in pancreatic $\beta$-cell determination including PDX1, NGN 3, SOX9, NKX6.1, MAFA, and MNX1 (144). For example, Zhou et al. reported that the reexpression of transcription factor NGN 3, combined with PDX1 and MAFA, can efficiently reprogram pancreatic exocrine cells into insulin-producing cells (145). Additionally, their study found that the overexpression of Pref-1-activated MAPK and AKT signaling can help to increase insulin synthesis via the differentiation of human pancreatic ductal cells into $\beta$-like cells (146). Recently, research has demonstrated that by disrupting $\alpha$ cell-specific TFs such as DNMT1 and ARX, the reprogramming of $\alpha$ cells to $\beta$ cells can be achieved (147). Until now, there has been a lack of direct evidence demonstrating that stem cells and their derived EVs can modify the process of reprogramming non-pancreatic cell into insulin-expression cells. However, Ribeiro et al. found that human pancreatic islet-derived EVs improve the differentiation of iPSC cluster culture in 3-D collagen hydrogel with increased pancreatic marker expression (148). Recently, Oh and colleagues showed that $\beta$-cell-derived EVs can directly trigger the differentiation of bone marrow mononucleated cells into insulin-producing cells (149). These findings suggest that stem cell-derived EVs may serve as possible mediators for the development of insulin-producing cells from non-beta pancreatic cells. Prospectively, investigating the function of stem cell-derived EVs on endogenous regeneration of $\beta$ cells will provide deep insights into the process of cell reprogramming.

\section{Protective Effects of Stem Cell-Derived EVs on Islet $\beta$ Cells and Pancreatic Islets}

The promotion of $\beta$-cell survival and functioning can be achieved via apoptosis protection. The apoptotic pathway mainly consists of two pathways-the extrinsic and intrinsic pathways. The extrinsic pathway is ignited by the cell surface death receptor (Fas and tumor necrosis factor receptor) bound with their ligand. The intrinsic pathway, also termed the "mitochondrial-mediated pathway", is triggered by the preapoptotic Bcl-2 family, leading to permeabilization of the mitochondrial outer membrane. Both pathways culminate in the activation of the caspase protease family, ultimately resulting in the dismantling of cells $(150,151)$. Autophagy is a cell survival mechanism that delays the cell death. There are increasing evidence supporting that coculture stem cells with $\beta$ cells can delay the apoptosis of $\beta$ cells $(152,153)$. Mechanistic studies have found that the secretome from stem cells can enhance autophagy and exert the protective effects on $\beta$ cells $(154,155)$. Recently, researchers found that EVs among MSC secretome play a powerful role in the anti-apoptosis of $\beta$ cells. Keshtkar et al. demonstrated that MSC-derived EVs can improve islet survival and function by upregulating insulin and vascular endothelial growth factor (VEGF) expressions (156). Furthermore, mechanistic studies have revealed that MSC-derived EVs preserve $\beta$-cell function, depending on their contained miRNA-21 for alleviating ER stress, and downregulate p38 MAPK phosphorylation to reduce hypoxia-induced apoptosis of $\beta$ cells (157). Furthermore, in vivo studies have affirmed these findings, demonstrating that the administration of EVs from MSC can restore insulin secretions by inhibiting STZ-induced $\beta$ cell apoptosis in T1D mouse models (158).

Additionally, stem cell-derived EVs have a strong ability to promote angiogenesis during the tissue repair. An in vitro study found that human bone marrow stem cells enhance islet vascularization and preserve islet function with significantly increased expressions of insulin (159). Moreover, administration of MSC-derived EVs can preserve the architecture of islets with longer survival time and increased insulin content in STZ-induced diabetic mice. Histologic analysis has demonstrated that treatment with EVs improves the level of CD31 expression in pancreatic islets (which are markers of endothelial cells), indicating the enhanced islet vascularization (160). Interestingly, Cantaluppi et al. utilized EVs from endothelial progenitor cells with the islet transplantation mice model. Their study demonstrated that these EVs carry proangiogenic miR-126 and miR-196 enhanced islet vascularization, leading to sustained $\beta$-cell function (161). Nie et al. showed that human mesenchymal stem cell (MSC)-derived exosomes can improve the survival ratio, viability, and function of neonatal porcine islet cell clusters under hypoxic conditions (162), which are key factors causing islet graft dysfunction (163). 
Recently, Gesmundo et al. reported that adipocyte-derived EVs regulated the survival and function of human pancreatic $\beta$ cells and pancreatic islets (164). For the role of EVs in islet transplantation, readers are encouraged to refer to the prior review (165). These findings support the idea that stem cellderived EVs are suitable candidates to improve the functioning and survival of $\beta$ cells for the treatment of T1D.

\section{Effects of Stem Cell-Derived EVs on Stem Cell Differentiation Toward $\beta$ Cells}

$\beta$-cell regeneration using stem cells means utilizing pluripotent stem cells with differentiation protocol to generate insulinproducing cells in vitro-a strategy for $\beta$-cell replacement therapy. Human pluripotent stem cells [either human embryonic stem cells (ESC) or induced pluripotent stem cells (iPS)] are attractive sources for $\beta$-cell differentiation since they can give rise to every cell type of the human body (166). To date, scientists have employed the multiple differentiation protocols, exposing cells to various growth factors and numerous signaling molecules in a particular sequence for differentiation of the cells into pancreatic endocrine cells $(167,168)$. Recently, other multipotent stem cells applied for the $\beta$-cell regeneration including MSCs and CB-SCs (169, 170). Interestingly, 3dimensional cultures promote the differentiation of stem cells into insulin-producing cells with increased insulin and c-peptide secretion (171-173). Currently, there is no evidence suggesting that stem cell-derived EVs can definitively affect the differentiation of stem cells into functional islet $\beta$ cells.

\section{CONCLUSIONS}

Currently, most clinical trials on EVs or exosomes are considering their function as valuable biomarkers for diagnosis and prognosis in a range of diseases. Based on their capabilities of immune modulations and anti-inflammation, some of the studies are actively exploring EVs as therapeutic carriers by using MSC-derived EVs in cases of chronic kidney disease (174), lung injury (175), and severe COVID-19 (176, 177). To date, a number of preclinical studies have implied the translational capability of stem cell-derived EVs to treat T1D through their multiple immunomodulations of different immune

\section{REFERENCES}

1. Bluestone JA, Herold K, Eisenbarth G. Genetics, Pathogenesis and Clinical Interventions in Type 1 Diabetes. Nature (2010) 464:1293-300. doi: 10.1038/nature08933

2. Deshpande AD, Harris-Hayes M, Schootman M. Epidemiology of Diabetes and Diabetes-Related Complications. Phys Ther (2008) 88:1254-64. doi: $10.2522 / \mathrm{ptj} .20080020$

3. Rewers M, Ludvigsson J. Environmental Risk Factors for Type 1 Diabetes. Lancet (London England) (2016) 387:2340-8. doi: 10.1016/S0140-6736(16) 30507-4

4. Rickels MR, Robertson RP. Pancreatic Islet Transplantation in Humans: Recent Progress and Future Directions. Endocr Rev (2019) 40:631-68. doi: 10.1210/er.2018-00154 cells and their potential to improve $\beta$-cell regeneration. That being said, only one clinical trial posted in ClinicalTrials.gov in 2014 (NCT02138331) did not report results. In comparison with their parent cells, stem cell-derived EVs may have good safety profiles and can be easily stored and transported as cell-free products without losing their functions. However, parent cells at different ex vivo culture conditions (e.g., culture medium with or without serum) may markedly affect their exosomes' biochemical and biophysical features including the quantity and quality of bioactive molecules. Thus, it will be essential to develop a scalable and reproducible Standard Operating Procedure (SOP) for the EV production. Stem cell-derived EVs carry cargos of enriched biomolecules (RNAs, proteins) that need to be further characterized, clarifying their unique and synergistic effects for the treatment of T1D.

Overcoming the autoimmunity and shortage of islet $\beta$ cells are two major issues for the treatment of T1D patients. Due to the limitations of native EVs such as the diversity, the low yield of EV production, as well as a short half-life and off-target effects of their actions post administration, it will be critical to direct a sufficient amount of EVs towards the specific targeting of autoimmune cells. Additionally, future attention should be placed on promoting the replication of residual $\beta$ cells in pancreatic islets. To this respect, using the bioengineered EVs may facilitate the clinical translation of EVs for T1D treatment. However, the toxicity, purity, potency, and stability of these bioengineered EVs are mandatory for the FDA approval in clinical trials. These practical challenges must be overcome before stem cell-derived or bioengineered EVs can achieve their full therapeutic potentials for T1D and other autoimmune diseases.

\section{AUTHOR CONTRIBUTIONS}

YZ contributed to concepts, article revising, and final approval of article. WH and XS drafted the article. HY, JS, HW, and YZ edited the review article. All authors contributed to the article and approved the submitted version.

\section{ACKNOWLEDGMENTS}

\author{
We appreciate Laura Zhao for English editing.
}

5. Choumerianou DM, Dimitriou H, Kalmanti M. Stem Cells: Promises Versus Limitations. Tissue Eng Part B Rev (2008) 14:53-60. doi: 10.1089/teb.2007.0216

6. Pagliuca FW, Millman JR, Gurtler M, Segel M, Van DA, Ryu JH, et al. Generation of Functional Human Pancreatic Beta Cells In Vitro. Cell (2014) 159:428-39. doi: 10.1016/j.cell.2014.09.040

7. Agulnick AD, Ambruzs DM, Moorman MA, Bhoumik A, Cesario RM, Payne JK, et al. Insulin-Producing Endocrine Cells Differentiated In Vitro From Human Embryonic Stem Cells Function in Macroencapsulation Devices In Vivo. Stem Cells Trans Med (2015) 4:1214-22. doi: 10.5966/ sctm.2015-0079

8. Kelly OG, Chan MY, Martinson LA, Kadoya K, Ostertag TM, Ross KG, et al. Cell-Surface Markers for the Isolation of Pancreatic Cell Types Derived From Human Embryonic Stem Cells. Nat Biotechnol (2011) 29:750-6. doi: $10.1038 /$ nbt.1931 
9. Sneddon JB, Tang Q, Stock P, Bluestone JA, Roy S, Desai T, et al. Stem Cell Therapies for Treating Diabetes: Progress and Remaining Challenges. Cell Stem Cell (2018) 22:810-23. doi: 10.1016/j.stem.2018.05.016

10. Minciacchi VR, Zijlstra A, Rubin MA, Di Vizio D. Extracellular Vesicles for Liquid Biopsy in Prostate Cancer: Where are We and Where are We Headed? Prostate Cancer Prostatic Dis (2017) 20:251-8. doi: 10.1038/ pcan.2017.7

11. Yáñez-Mó M, Siljander PR, Andreu Z, Zavec AB, Borràs FE, Buzas EI, et al. Biological Properties of Extracellular Vesicles and Their Physiological Functions. J Extracell Vesicles (2015) 4:27066. doi: 10.3402/jev.v4.27066

12. Pang B, Zhu Y, Ni J, Thompson J, Malouf D, Bucci J, et al. Extracellular Vesicles: The Next Generation of Biomarkers for Liquid Biopsy-Based Prostate Cancer Diagnosis. Theranostics (2020) 10:2309-26. doi: 10.7150/ thno. 39486

13. Wiklander OPB, Brennan M.Á., Lötvall J, Breakefield XO, El Andaloussi S. Advances in Therapeutic Applications of Extracellular Vesicles. Sci Trans Med (2019) 11:eaav8521. doi: 10.1126/scitranslmed.aav8521

14. Rogers RG, Ciullo A, Marbán E, Ibrahim AG. Extracellular Vesicles as Therapeutic Agents for Cardiac Fibrosis. Front Physiol (2020) 11:479. doi: 10.3389/fphys.2020.00479

15. Liu W, Li L, Rong Y, Qian D, Chen J, Zhou Z, et al. Hypoxic Mesenchymal Stem Cell-Derived Exosomes Promote Bone Fracture Healing by the Transfer of miR-126. Acta Biomater (2020) 103:196-212. doi: 10.1016/ j.actbio.2019.12.020

16. Xie M, Xiong W, She Z, Wen Z, Abdirahman AS, Wan W, et al. Immunoregulatory Effects of Stem Cell-Derived Extracellular Vesicles on Immune Cells. Front Immunol (2020) 11:13. doi: 10.3389/fimmu.2020.00013

17. Pang H, Luo S, Xiao Y, Xia Y, Li X, Huang G, et al. Emerging Roles of Exosomes in T1DM. Front Immunol (2020) 11:593348. doi: 10.3389/ fimmu.2020.593348

18. Wen D, Peng Y, Liu D, Weizmann Y, Mahato RI. Mesenchymal Stem Cell and Derived Exosome as Small RNA Carrier and Immunomodulator to Improve Islet Transplantation. J Control Release (2016) 238:166-75. doi: 10.1016/j.jconrel.2016.07.044

19. El Andaloussi S, Mäger I, Breakefield XO, Wood MJA. Extracellular Vesicles: Biology and Emerging Therapeutic Opportunities. Nat Rev Drug Discov (2013) 12:347-57. doi: 10.1038/nrd3978

20. Abels ER, Breakefield XO. Introduction to Extracellular Vesicles: Biogenesis, RNA Cargo Selection, Content, Release, and Uptake. Cell Mol Neurobiol (2016) 36:301-12. doi: 10.1007/s10571-016-0366-z

21. Colombo M, Raposo G, Théry C. Biogenesis, Secretion, and Intercellular Interactions of Exosomes and Other Extracellular Vesicles. Annu Rev Cell Dev Biol (2014) 30:255-89. doi: 10.1146/annurev-cellbio-101512-122326

22. Hu W, Song X, Yu H, Sun J, Zhao Y. Therapeutic Potentials of Extracellular Vesicles for the Treatment of Diabetes and Diabetic Complications. Int J Mol Sci (2020) 21:5163. doi: 10.3390/ijms21145163

23. Gurunathan S, Kang MH, Jeyaraj M, Qasim M, Kim JH. Review of the Isolation, Characterization, Biological Function, and Multifarious Therapeutic Approaches of Exosomes. Cells (2019) 8:307. doi: 10.3390/cells8040307

24. Carnino JM, Lee H, Jin Y. Isolation and Characterization of Extracellular Vesicles From Broncho-Alveolar Lavage Fluid: A Review and Comparison of Different Methods. Respir Res (2019) 20:240. doi: 10.1186/s12931-019-1210-Z

25. Li X, Corbett AL, Taatizadeh E, Tasnim N, Little JP, Garnis C, et al. Challenges and Opportunities in Exosome Research-Perspectives From Biology, Engineering, and Cancer Therapy. APL Bioeng (2019) 3:011503. doi: $10.1063 / 1.5087122$

26. Yang D, Zhang W, Zhang H, Zhang F, Chen L, Ma L, et al. Progress, Opportunity, and Perspective on Exosome Isolation - Efforts for Efficient Exosome-Based Theranostics. Theranostics (2020) 10:3684-707. doi: $10.7150 /$ thno. 41580

27. Zaborowski MP, Balaj L, Breakefield XO, Lai CP. Extracellular Vesicles: Composition, Biological Relevance, and Methods of Study. Bioscience (2015) 65:783-97. doi: 10.1093/biosci/biv084

28. Huotari J, Helenius A. Endosome Maturation. EMBO J (2011) 30:3481-500. doi: 10.1038/emboj.2011.286

29. Samanta S, Rajasingh S, Drosos N, Zhou Z, Dawn B, Rajasingh J. Exosomes: New Molecular Targets of Diseases. Acta Pharmacol Sin (2018) 39:501-13. doi: 10.1038 /aps.2017.162
30. Doyle LM, Wang MZ. Overview of Extracellular Vesicles, Their Origin, Composition, Purpose, and Methods for Exosome Isolation and Analysis. Cells 8 (2019) 8:727. doi: 10.3390/cells8070727

31. Willms E, Cabañas C, Mäger I, Wood MJA, Vader P. Extracellular Vesicle Heterogeneity: Subpopulations, Isolation Techniques, and Diverse Functions in Cancer Progression. Front Immunol (2018) 9:738. doi: 10.3389/fimmu.2018.00738

32. Xu X, Lai Y, Hua ZC. Apoptosis and Apoptotic Body: Disease Message and Therapeutic Target Potentials. Biosci Rep (2019) 39:BSR20180992. doi: 10.1042/BSR20180992

33. Jayaseelan VP. Emerging Role of Exosomes as Promising Diagnostic Tool for Cancer. Cancer Gene Ther (2020) 27:395-8. doi: 10.1038/s41417-019-0136-4

34. Urbanelli L, Buratta S, Sagini K, Ferrara G, Lanni M, Emiliani C. ExosomeBased Strategies for Diagnosis and Therapy. Recent Pat CNS Drug Discov (2015) 10:10-27. doi: 10.2174/1574889810666150702124059

35. Chen G, Huang AC, Zhang W, Zhang G, Wu M, Xu W, et al. Exosomal PDL1 Contributes to Immunosuppression and is Associated With Anti-PD-1 Response. Nature (2018) 560:382-6. doi: 10.1038/s41586-018-0392-8

36. Fernández-Messina L, Gutiérrez-Vázquez C, Rivas-García E, Sánchez-Madrid F, de la Fuente H. Immunomodulatory Role of microRNAs Transferred by Extracellular Vesicles. Biol Cell (2015) 107:61-77. doi: 10.1111/boc.201400081

37. Tesovnik T, Kovač J, Pohar K, Hudoklin S, Dovč K, Bratina N, et al. Extracellular Vesicles Derived Human-miRNAs Modulate the Immune System in Type 1 Diabetes. Front Cell Dev Biol (2020) 8:202. doi: 10.3389/ fcell.2020.00202

38. Wiedeman AE, Muir VS, Rosasco MG, DeBerg HA, Presnell S, Haas B, et al. Autoreactive CD8+ T Cell Exhaustion Distinguishes Subjects With Slow Type 1 Diabetes Progression. J Clin Invest (2020) 130:480-90. doi: 10.1172/ JCI126595

39. Bevan MJ. Helping the CD8+ T-Cell Response. Nat Rev Immunol (2004) 4:595-602. doi: 10.1038/nri1413

40. Espinosa-Carrasco G, Le Saout C, Fontanaud P, Stratmann T, Mollard P, Schaeffer M, et al. CD4+ T Helper Cells Play a Key Role in Maintaining Diabetogenic CD8+ T Cell Function in the Pancreas. Front Immunol 8 (2018) 8:2001. doi: 10.3389/fimmu.2017.02001

41. Tay RE, Richardson EK, Toh HC. Revisiting the Role of CD4+ T Cells in Cancer Immunotherapy-New Insights Into Old Paradigms. Cancer Gene Ther (2020) 28:5-17. doi: 10.1038/s41417-020-0183-x

42. Schallenberg S, Kretschmer K. New Insight Into Type 1 Diabetes Development: Resolving Early Diabetogenic CD4(+) T Cell Responses That Precede Seroconversion. Ann Transl Med (2018) 6:58. doi: 10.21037/ atm.2017.12.14

43. Shao F, Zheng P, Yu D, Zhou Z, Jia L. Follicular Helper T Cells in Type 1 Diabetes. FASEB J (2020) 34:30-40. doi: 10.1096/fj.201901637R

44. Solt LA, Burris TP. Th17 Cells in Type 1 Diabetes: A Future Perspective. Diabetes Manag (Lond) (2015) 5:247-50. doi: 10.2217/dmt.15.19

45. Samuel RO, Ervolino E, de Azevedo Queiroz Í O, Azuma MM, Ferreira GT, Cintra LTA. Th1/Th2/Th17/Treg Balance in Apical Periodontitis of Normoglycemic and Diabetic Rats. J Endod (2019) 45:1009-15. doi: 10.1016/j.joen.2019.05.003

46. Vaseghi H, Jadali Z. Th1/Th2 Cytokines in Type 1 Diabetes: Relation to Duration of Disease and Gender. Indian J Endocrinol Metab (2016) 20:3126. doi: 10.4103/2230-8210.180002

47. Cabrera SM, Rigby MR, Mirmira RG. Targeting Regulatory T Cells in the Treatment of Type 1 Diabetes Mellitus. Curr Mol Med (2012) 12:1261-72. doi: $10.2174 / 156652412803833634$

48. Bluestone JA, Buckner JH, Fitch M, Gitelman SE, Gupta S, Hellerstein MK, et al. Type 1 Diabetes Immunotherapy Using Polyclonal Regulatory T Cells. Sci Transl Med (2015) 7:315ra189. doi: 10.1126/scitranslmed.aad4134

49. Cabello-Kindelan C, Mackey S, Sands A, Rodriguez J, Vazquez C, Pugliese A, et al. Immunomodulation Followed by Antigen-Specific T(reg) Infusion Controls Islet Autoimmunity. Diabetes (2020) 69:215-27. doi: 10.2337/ db19-0061

50. Crotty S. T Follicular Helper Cell Differentiation, Function, and Roles in Disease. Immunity (2014) 41:529-42. doi: 10.1016/j.immuni.2014.10.004

51. Kenefeck R, Wang CJ, Kapadi T, Wardzinski L, Attridge K, Clough LE, et al. Follicular Helper T Cell Signature in Type 1 Diabetes. J Clin Invest (2015) 125:292-303. doi: 10.1172/JCI76238 
52. Fiorina P, Jurewicz M, Augello A, Vergani A, Dada S, La Rosa S, et al. Immunomodulatory Function of Bone Marrow-Derived Mesenchymal Stem Cells in Experimental Autoimmune Type 1 Diabetes. J Immunol (2009) 183:993-1004. doi: 10.4049/jimmunol.0900803

53. Luz-Crawford P, Kurte M, Bravo-Alegría J, Contreras R, Nova-Lamperti E, Tejedor G, et al. Mesenchymal Stem Cells Generate a CD4+CD25+Foxp3+ Regulatory T Cell Population During the Differentiation Process of Th1 and Th17 Cells. Stem Cell Res Ther (2013) 4:65. doi: 10.1186/scrt216

54. Azevedo RI, Minskaia E, Fernandes-Platzgummer A, Vieira AIS, da Silva CL, Cabral JMS, et al. Mesenchymal Stromal Cells Induce Regulatory T Cells via Epigenetic Conversion of Human Conventional CD4 T Cells In Vitro. Stem Cells (2020) 38:1007-19. doi: 10.1002/stem.3185

55. Zhao Y, Jiang Z, Zhao T, Ye M, Hu C, Yin Z, et al. Reversal of Type 1 Diabetes via Islet Beta Cell Regeneration Following Immune Modulation by Cord Blood-Derived Multipotent Stem Cells. BMC Med (2012) 10:3. doi: 10.1186/1741-7015-10-3

56. Delgado E, Perez-Basterrechea M, Suarez-Alvarez B, Zhou H, Revuelta EM, Garcia-Gala JM, et al. Modulation of Autoimmune T-Cell Memory by Stem Cell Educator Therapy: Phase 1/2 Clinical Trial. EBioMedicine (2015) 2:2024-36. doi: 10.1016/j.ebiom.2015.11.003

57. Hu W, Song X, Yu H, Sun J, Zhao Y. Released Exosomes Contribute to the Immune Modulation of Cord Blood-Derived Stem Cells. Front Immunol (2020) 11:165. doi: 10.3389/fimmu.2020.00165

58. Lee S, Kim S, Chung H, Moon JH, Kang SJ, Park CG. Mesenchymal Stem Cell-Derived Exosomes Suppress Proliferation of T Cells by Inducing Cell Cycle Arrest Through P27kip1/Cdk2 Signaling. Immunol Lett (2020) 225:16-22. doi: 10.1016/j.imlet.2020.06.006

59. Zhang B, Yeo RWY, Lai RC, Sim EWK, Chin KC, Lim SK. Mesenchymal Stromal Cell Exosome-Enhanced Regulatory T-Cell Production Through an Antigen-Presenting Cell-Mediated Pathway. Cytotherapy (2018) 20:687-96. doi: 10.1016/j.jcyt.2018.02.372

60. Cheng A, Choi D, Lora M, Shum-Tim D, Rak J, Colmegna I. Human Multipotent Mesenchymal Stromal Cells Cytokine Priming Promotes RAB27B-Regulated Secretion of Small Extracellular Vesicles With Immunomodulatory Cargo. Stem Cell Res Ther (2020) 11:539. doi: 10.1186/s13287-020-02050-6

61. Li Y, Wang F, Guo R, Zhang Y, Chen D, Li X, et al. Exosomal Sphingosine 1Phosphate Secreted by Mesenchymal Stem Cells Regulated Treg/Th17 Balance in Aplastic Anemia. IUBMB Life (2019) 71:1284-92. doi: 10.1002/ iub. 2035

62. Shigemoto-Kuroda T, Oh JY, Kim DK, Jeong HJ, Park SY, Lee HJ, et al. MSC-Derived Extracellular Vesicles Attenuate Immune Responses in Two Autoimmune Murine Models: Type 1 Diabetes and Uveoretinitis. Stem Cell Rep (2017) 8:1214-25. doi: 10.1016/j.stemcr.2017.04.008

63. Favaro E, Carpanetto A, Caorsi C, Giovarelli M, Angelini C, Cavallo-Perin P, et al. Human Mesenchymal Stem Cells and Derived Extracellular Vesicles Induce Regulatory Dendritic Cells in Type 1 Diabetic Patients. Diabetologia (2016) 59:325-33. doi: 10.1007/s00125-015-3808-0

64. Favaro E, Carpanetto A, Lamorte S, Fusco A, Caorsi C, Deregibus MC, et al. Human Mesenchymal Stem Cell-Derived Microvesicles Modulate T Cell Response to Islet Antigen Glutamic Acid Decarboxylase in Patients With Type 1 Diabetes. Diabetologia (2014) 57:1664-73. doi: 10.1007/s00125-0143262-4

65. Nojehdehi S, Soudi S, Hesampour A, Rasouli S, Soleimani M, Hashemi SM. Immunomodulatory Effects of Mesenchymal Stem Cell-Derived Exosomes on Experimental Type-1 Autoimmune Diabetes. J Cell Biochem (2018) 119:9433-43. doi: $10.1002 / j \mathrm{cb} .27260$

66. Remmerie A, Scott CL. Macrophages and Lipid Metabolism. Cell Immunol (2018) 330:27-42. doi: 10.1016/j.cellimm.2018.01.020

67. Orliaguet L, Dalmas E, Drareni K, Venteclef N, Alzaid F. Mechanisms of Macrophage Polarization in Insulin Signaling and Sensitivity. Front Endocrinol (2020) 11:62. doi: 10.3389/fendo.2020.00062

68. Atri C, Guerfali FZ, Laouini D. Role of Human Macrophage Polarization in Inflammation During Infectious Diseases. Int J Mol Sci (2018) 19:1801. doi: 10.3390/ijms 19061801

69. Viola A, Munari F, Sánchez-Rodríguez R, Scolaro T, Castegna A. The Metabolic Signature of Macrophage Responses. Front Immunol (2019) 10:1462. doi: $10.3389 /$ fimmu.2019.01462
70. Espinoza-Jiménez A, Peón AN, Terrazas LI. Alternatively Activated Macrophages in Types 1 and 2 Diabetes. Mediators Inflamm (2012) 2012:815953. doi: $10.1155 / 2012 / 815953$

71. Shouval DS, Biswas A, Goettel JA, McCann K, Conaway E, Redhu NS, et al. Interleukin-10 Receptor Signaling in Innate Immune Cells Regulates Mucosal Immune Tolerance and Anti-Inflammatory Macrophage Function. Immunity (2014) 40:706-19. doi: 10.1016/j.immuni.2014.03.011

72. Zigmond E, Bernshtein B, Friedlander G, Walker CR, Yona S, Kim KW, et al. Macrophage-Restricted Interleukin-10 Receptor Deficiency, But Not IL-10 Deficiency, Causes Severe Spontaneous Colitis. Immunity (2014) 40:720-33. doi: 10.1016/j.immuni.2014.03.012

73. Yu T, Gan S, Zhu Q, Dai D, Li N, Wang H, et al. Modulation of M2 Macrophage Polarization by the Crosstalk Between Stat6 and Trim24. Nat Commun (2019) 10:4353. doi: 10.1038/s41467-019-12384-2

74. Mantovani A, Biswas SK, Galdiero MR, Sica A, Locati M. Macrophage Plasticity and Polarization in Tissue Repair and Remodelling. J Pathol (2013) 229:176-85. doi: 10.1002/path.4133

75. Noël W, Raes G, Hassanzadeh Ghassabeh G, De Baetselier P, Beschin A. Alternatively Activated Macrophages During Parasite Infections. Trends Parasitol (2004) 20:126-33. doi: 10.1016/j.pt.2004.01.004

76. Dalmas E, Lehmann FM, Dror E, Wueest S, Thienel C, Borsigova M, et al. Interleukin-33-Activated Islet-Resident Innate Lymphoid Cells Promote Insulin Secretion Through Myeloid Cell Retinoic Acid Production. Immunity (2017) 47:928-942.e7. doi: 10.1016/j.immuni.2017.10.015

77. Carrero JA, McCarthy DP, Ferris ST, Wan X, Hu H, Zinselmeyer BH, et al. Resident Macrophages of Pancreatic Islets Have a Seminal Role in the Initiation of Autoimmune Diabetes of NOD Mice. Proc Natl Acad Sci USA (2017) 114:E10418-27. doi: 10.1073/pnas.1713543114

78. Marro BS, Legrain S, Ware BC, Oldstone MB. Macrophage IFN-I Signaling Promotes Autoreactive T Cell Infiltration Into Islets in Type 1 Diabetes Model. JCI Insight (2019) 4:e125067. doi: 10.1172/jci.insight.125067

79. Galvão Tessaro FH, Ayala TS, Bella LM, Martins JO. Macrophages From a Type 1 Diabetes Mouse Model Present Dysregulated Pl3K/AKT, ERK 1/2 and SAPK/JNK Levels. Immunobiology (2020) 225:151879. doi: 10.1016/ j.imbio.2019.11.014

80. Pavlou S, Lindsay J, Ingram R, Xu H, Chen M. Sustained High Glucose Exposure Sensitizes Macrophage Responses to Cytokine Stimuli But Reduces Their Phagocytic Activity. BMC Immunol (2018) 19:24. doi: 10.1186/s12865018-0261-0

81. Ferris ST, Zakharov PN, Wan X, Calderon B, Artyomov MN, Unanue ER, et al. The Islet-Resident Macrophage is in an Inflammatory State and Senses Microbial Products in Blood. J Exp Med (2017) 214:2369-85. doi: 10.1084/ jem.20170074

82. Zhao H, Shang Q, Pan Z, Bai Y, Li Z, Zhang H, et al. Exosomes From Adipose-Derived Stem Cells Attenuate Adipose Inflammation and Obesity Through Polarizing M2 Macrophages and Beiging in White Adipose Tissue. Diabetes (2018) 67:235-47. doi: 10.2337/db17-0356

83. Heo JS, Choi Y, Kim HO. Adipose-Derived Mesenchymal Stem Cells Promote M2 Macrophage Phenotype Through Exosomes. Stem Cells Int (2019) 2019:7921760. doi: 10.1155/2019/7921760

84. Zhao J, Li X, Hu J, Chen F, Qiao S, Sun X, et al. Mesenchymal Stromal CellDerived Exosomes Attenuate Myocardial Ischaemia-Reperfusion Injury Through miR-182-Regulated Macrophage Polarization. Cardiovasc Res (2019) 115:1205-16. doi: 10.1093/cvr/cvz040

85. Liu W, Yu M, Xie D, Wang L, Ye C, Zhu Q, et al. Melatonin-Stimulated MSC-Derived Exosomes Improve Diabetic Wound Healing Through Regulating Macrophage M1 and M2 Polarization by Targeting the PTEN/ AKT Pathway. Stem Cell Res Ther (2020) 11:259. doi: 10.1186/s13287-02001756-x

86. Kink JA, Forsberg MH, Reshetylo S, Besharat S, Childs CJ, Pederson JD, et al. Macrophages Educated With Exosomes From Primed Mesenchymal Stem Cells Treat Acute Radiation Syndrome by Promoting Hematopoietic Recovery. Biol Blood Marrow Transplant (2019) 25:2124-33. doi: 10.1016/ j.bbmt.2019.07.026

87. Chamberlain CS, Kink JA, Wildenauer LA, McCaughey M, Henry K, Spiker AM, et al. Exosome-Educated Macrophages and Exosomes Differentially Improve Ligament Healing. Stem Cells (2021) 39:55-61. doi: 10.1002/ stem.3291 
88. Hu W, Song X, Yu H, Sun J, Zhao Y. Differentiation of Monocytes Into Phenotypically Distinct Macrophages After Treatment With Human Cord Blood Stem Cell (CB-SC)-Derived Exosomes. J Vis Exp (2020). doi: 10.3791/ 61562

89. Li Y, Yan B, Wang H, Li H, Li Q, Zhao D, et al. Hair Regrowth in Alopecia Areata Patients Following Stem Cell Educator Therapy. BMC Med (2015) 13:87. doi: 10.1186/s12916-015-0331-6

90. Creusot RJ, Giannoukakis N, Trucco M, Clare-Salzler MJ, Fathman CG. It's Time to Bring Dendritic Cell Therapy to Type 1 Diabetes. Diabetes (2014) 63:20-30. doi: $10.2337 / \mathrm{db} 13-0886$

91. Hotta-Iwamura C, Tarbell KV. Type 1 Diabetes Genetic Susceptibility and Dendritic Cell Function: Potential Targets for Treatment. J Leukoc Biol (2016) 100:65-80. doi: 10.1189/jlb.3MR1115-500R

92. Ghaemi Oskouie F, Shameli A, Yang A, Desrosiers MD, Mucsi AD, Blackburn MR, et al. High Levels of Adenosine Deaminase on Dendritic Cells Promote Autoreactive T Cell Activation and Diabetes in Nonobese Diabetic Mice. J Immunol (2011) 186:6798-806. doi: 10.4049/jimmunol.1004222

93. Jung YJ, Ju SY, Yoo ES, Cho S, Cho KA, Woo SY, et al. MSC-DC Interactions: MSC Inhibit Maturation and Migration of BM-Derived DC. Cytotherapy (2007) 9:451-8. doi: 10.1080/14653240701452057

94. Lu Z, Chang W, Meng S, Xu X, Xie J, Guo F, et al. Mesenchymal Stem Cells Induce Dendritic Cell Immune Tolerance via Paracrine Hepatocyte Growth Factor to Alleviate Acute Lung Injury. Stem Cell Res Ther (2019) 10:372. doi: 10.1186/s13287-019-1488-2

95. Shahir M, Mahmoud Hashemi S, Asadirad A, Varahram M, KazempourDizaji M, Folkerts G, et al. Effect of Mesenchymal Stem Cell-Derived Exosomes on the Induction of Mouse Tolerogenic Dendritic Cells. J Cell Physiol (2020) 235:7043-55. doi: 10.1002/jcp.29601

96. Reis M, Mavin E, Nicholson L, Green K, Dickinson AM, Wang XN. Mesenchymal Stromal Cell-Derived Extracellular Vesicles Attenuate Dendritic Cell Maturation and Function. Front Immunol (2018) 9:2538. doi: $10.1002 / j \mathrm{jcp} .29601$

97. Wu XQ, Yan TZ, Wang ZW, Wu X, Cao GH, Zhang C. BM-MSCs-Derived Microvesicles Promote Allogeneic Kidney Graft Survival Through Enhancing Micro-146a Expression of Dendritic Cells. Immunol Lett (2017) 191:55-62. doi: 10.1016/j.imlet.2017.09.010

98. Poirot L, Benoist C, Mathis D. Natural Killer Cells Distinguish Innocuous and Destructive Forms of Pancreatic Islet Autoimmunity. Proc Natl Acad Sci USA (2004) 101:8102-7. doi: 10.1073/pnas.0402065101

99. Lehuen A, Diana J, Zaccone P, Cooke A. Immune Cell Crosstalk in Type 1 Diabetes. Nat Rev Immunol (2010) 10:501-13. doi: 10.1038/nri2787

100. Baxter AG, Smyth MJ. The Role of NK Cells in Autoimmune Disease. Autoimmunity (2002) 35:1-14. doi: 10.1080/08916930290005864

101. Rodacki M, Svoren B, Butty V, Besse W, Laffel L, Benoist C, et al. Altered Natural Killer Cells in Type 1 Diabetic Patients. Diabetes (2007) 56:177-85. doi: $10.2337 / \mathrm{db} 06-0493$

102. Alba A, Planas R, Clemente X, Carrillo J, Ampudia R, Puertas MC, et al. Natural Killer Cells are Required for Accelerated Type 1 Diabetes Driven by Interferon-Beta. Clin Exp Immunol (2008) 151:467-75. doi: 10.1111/j.13652249.2007.03580.x

103. Sotiropoulou PA, Perez SA, Gritzapis AD, Baxevanis CN, Papamichail M. Interactions Between Human Mesenchymal Stem Cells and Natural Killer Cells. Stem Cells (2006) 24:74-85. doi: 10.1634/stemcells.2004-0359

104. Spaggiari GM, Capobianco A, Abdelrazik H, Becchetti F, Mingari MC, Moretta L. Mesenchymal Stem Cells Inhibit Natural Killer-Cell Proliferation, Cytotoxicity, and Cytokine Production: Role of Indoleamine 2,3-Dioxygenase and Prostaglandin E2. Blood (2008) 111:1327-33. doi: 10.1182/blood-2007-02-074997

105. Kordelas L, Rebmann V, Ludwig AK, Radtke S, Ruesing J, Doeppner TR, et al. MSC-Derived Exosomes: A Novel Tool to Treat Therapy-Refractory Graft-Versus-Host Disease. Leukemia (2014) 28:970-3. doi: 10.1038/ leu.2014.41

106. Fan Y, Herr F, Vernochet A, Mennesson B, Oberlin E, Durrbach A. Human Fetal Liver Mesenchymal Stem Cell-Derived Exosomes Impair Natural Killer Cell Function. Stem Cells Dev (2019) 28:44-55. doi: 10.1089/scd.2018.0015

107. Häusser-Kinzel S, Weber MS. The Role of B Cells and Antibodies in Multiple Sclerosis, Neuromyelitis Optica, and Related Disorders. Front Immunol (2019) 10:201. doi: 10.3389/fimmu.2019.00201
108. Hampe CS. B Cell in Autoimmune Diseases. Scientifica (Cairo) (2012) 2012:215308. doi: 10.6064/2012/215308

109. Xiu Y, Wong CP, Bouaziz JD, Hamaguchi Y, Wang Y, Pop SM, et al. B Lymphocyte Depletion by CD20 Monoclonal Antibody Prevents Diabetes in Nonobese Diabetic Mice Despite Isotype-Specific Differences in Fc Gamma R Effector Functions. J Immunol (2008) 180:2863-75. doi: 10.4049/ jimmunol.180.5.2863

110. Hu CY, Rodriguez-Pinto D, Du W, Ahuja A, Henegariu O, Wong FS, et al. Treatment With CD20-Specific Antibody Prevents and Reverses Autoimmune Diabetes in Mice. J Clin Invest (2007) 117:3857-67. doi: 10.1172/JCI32405

111. Pescovitz MD, Greenbaum CJ, Bundy B, Becker DJ, Gitelman SE, Goland R, et al. B-Lymphocyte Depletion With Rituximab and $\beta$-Cell Function: TwoYear Results. Diabetes Care (2014) 37:453-9. doi: 10.2337/dc13-0626

112. Pescovitz MD, Greenbaum CJ, Krause-Steinrauf H, Becker DJ, Gitelman SE, Goland R, et al. Rituximab, B-Lymphocyte Depletion, and Preservation of Beta-Cell Function. N Engl J Med (2009) 361:2143-52. doi: 10.1056/ NEJMoa0904452

113. Franquesa M, Hoogduijn MJ, Bestard O, Grinyó JM. Immunomodulatory Effect of Mesenchymal Stem Cells on B Cells. Front Immunol (2012) 3:212. doi: 10.3389/fimmu.2012.00212

114. Corcione A, Benvenuto F, Ferretti E, Giunti D, Cappiello V, Cazzanti F, et al. Human Mesenchymal Stem Cells Modulate B-Cell Functions. Blood (2006) 107:367-72. doi: 10.1182/blood-2005-07-2657

115. Khare D, Or R, Resnick I, Barkatz C, Almogi-Hazan O, Avni B. Mesenchymal Stromal Cell-Derived Exosomes Affect mRNA Expression and Function of B-Lymphocytes. Front Immunol (2018) 9:3053. doi: 10.3389/fimmu.2018.03053

116. Adamo A, Brandi J, Caligola S, Delfino P, Bazzoni R, Carusone R, et al. Extracellular Vesicles Mediate Mesenchymal Stromal Cell-Dependent Regulation of B Cell PI3K-AKT Signaling Pathway and Actin Cytoskeleton. Front Immunol (2019) 10:446. doi: 10.3389/fimmu.2019.00446

117. Wang Y, Xiao Y, Zhong L, Ye D, Zhang J, Tu Y, et al. Increased Neutrophil Elastase and Proteinase 3 and Augmented NETosis are Closely Associated With $\beta$-Cell Autoimmunity in Patients With Type 1 Diabetes. Diabetes (2014) 63:4239-48. doi: 10.2337/db14-0480

118. Battaglia M. Neutrophils and Type 1 Autoimmune Diabetes. Curr Opin Hematol (2014) 21:8-15. doi: 10.1097/MOH.0000000000000008

119. Yano H, Kinoshita M, Fujino K, Nakashima M, Yamamoto Y, Miyazaki H, et al. Insulin Treatment Directly Restores Neutrophil Phagocytosis and Bactericidal Activity in Diabetic Mice and Thereby Improves Surgical Site Staphylococcus Aureus Infection. Infect Immun (2012) 80:4409-16. doi: 10.1128/IAI.00787-12

120. Wang L-T, Wang H-H, Chiang H-C, Huang L-Y, Chiu S-K, Siu LK, et al. Human Placental MSC-Secreted IL-1 $\beta$ Enhances Neutrophil Bactericidal Functions During Hypervirulent Klebsiella Infection. Cell Rep (2020) 32:108188. doi: 10.1016/j.celrep.2020.108188

121. Raffaghello L, Bianchi G, Bertolotto M, Montecucco F, Busca A, Dallegri F, et al. Human Mesenchymal Stem Cells Inhibit Neutrophil Apoptosis: A Model for Neutrophil Preservation in the Bone Marrow Niche. Stem Cells (2008) 26:151-62. doi: 10.1634/stemcells.2007-0416

122. Cassatella MA, Mosna F, Micheletti A, Lisi V, Tamassia N, Cont C, et al. Toll-Like Receptor-3-Activated Human Mesenchymal Stromal Cells Significantly Prolong the Survival and Function of Neutrophils. Stem Cells (2011) 29:1001-11. doi: 10.1002/stem.651

123. Taghavi-Farahabadi M, Mahmoudi M, Rezaei N, Hashemi SM. Wharton's Jelly Mesenchymal Stem Cells Exosomes and Conditioned Media Increased Neutrophil Lifespan and Phagocytosis Capacity. Immunol Invest (2020) 50:1042-57. doi: 10.1080/08820139.2020.1801720

124. Mahmoudi M, Taghavi-Farahabadi M, Namaki S, Baghaei K, Rayzan E, Rezaei $\mathrm{N}$, et al. Exosomes Derived From Mesenchymal Stem Cells Improved Function and Survival of Neutrophils From Severe Congenital Neutropenia Patients In Vitro. Hum Immunol (2019) 80:990-8. doi: 10.1016/j.humimm.2019.10.006

125. Steiner DJ, Kim A, Miller K, Hara M. Pancreatic Islet Plasticity: Interspecies Comparison of Islet Architecture and Composition. Islets (2010) 2:135-45. doi: 10.4161/isl.2.3.11815

126. Cabrera O, Berman DM, Kenyon NS, Ricordi C, Berggren P-O, Caicedo A. The Unique Cytoarchitecture of Human Pancreatic Islets has Implications 
for Islet Cell Function. Proc Natl Acad Sci (2006) 103:2334-9. doi: 10.1073/ pnas.0510790103

127. Roep BO, Thomaidou S, van Tienhoven R, Zaldumbide A. Type 1 Diabetes Mellitus as a Disease of the $\beta$-Cell (do Not Blame the Immune System)? Nat Rev Endocrinol (2021) 17:150-61. doi: 10.1038/s41574-020-00443-4

128. Zhong F, Jiang Y. Endogenous Pancreatic $\beta$ Cell Regeneration: A Potential Strategy for the Recovery of $\beta$ Cell Deficiency in Diabetes. Front Endocrinol (2019) 10:101. doi: 10.3389/fendo.2019.00101

129. Benthuysen JR, Carrano AC, Sander M. Advances in $\beta$ Cell Replacement and Regeneration Strategies for Treating Diabetes. J Clin Invest (2016) 126:365160. doi: 10.1172/JCI87439

130. Rattananinsruang P, Dechsukhum C, Leeanansaksiri W. Establishment of Insulin-Producing Cells From Human Embryonic Stem Cells Underhypoxic Condition for Cell Based Therapy. Front Cell Dev Biol (2018) 6:49. doi: 10.3389/fcell.2018.00049

131. Memon B, Abdelalim EM. Stem Cell Therapy for Diabetes: Beta Cells Versus Pancreatic Progenitors. Cells (2020) 9:283. doi: 10.3390/cells9020283

132. Bai C, Ren Q, Liu H, Li X, Guan W, Gao Y. miR-212/132-Enriched Extracellular Vesicles Promote Differentiation of Induced Pluripotent Stem Cells Into Pancreatic Beta Cells. Front Cell Dev Biol (2021) 9. doi: 10.3389/ fcell.2021.673231

133. Chidester S, Livinski AA, Fish AF, Joseph PV. The Role of Extracellular Vesicles in $\beta$-Cell Function and Viability: A Scoping Review. Front Endocrinol (2020) 11. doi: 10.3389/fendo.2020.00375

134. Jurczyk A, Bortell R, Alonso LC. Human $\beta$-Cell Regeneration: Progress, Hurdles, and Controversy. Curr Opin Endocrinol Diabetes Obes (2014) 21:102-8. doi: 10.1097/MED.0000000000000042

135. Jiang WJ, Peng YC, Yang KM. Cellular Signaling Pathways Regulating $\beta$-Cell Proliferation as a Promising Therapeutic Target in the Treatment of Diabetes. Exp Ther Med (2018) 16:3275-85. doi: 10.3892/etm.2018.6603

136. Shirakawa J, Fernandez M, Takatani T, El Ouaamari A, Jungtrakoon P, Okawa ER, et al. Insulin Signaling Regulates the FoxM1/PLK1/CENP-A Pathway to Promote Adaptive Pancreatic $\beta$ Cell Proliferation. Cell Metab (2017) 25:868-882.e5. doi: 10.1016/j.cmet.2017.02.004

137. Jiang Y, Fischbach S, Xiao X. The Role of the Tgf $\beta$ Receptor Signaling Pathway in Adult Beta Cell Proliferation. Int J Mol Sci 19 (2018) 19:3136. doi: 10.3390/ijms 19103136

138. Keefe MD, Wang H, De La OJ, Khan A, Firpo MA, Murtaugh LC. $\beta$-Catenin is Selectively Required for the Expansion and Regeneration of Mature Pancreatic Acinar Cells in Mice. Dis Model Mech (2012) 5:503-14. doi: 10.1242/dmm.007799

139. Wang H, Ren $Y, H u X$, Ma M, Wang X, Liang H, et al. Effect of Wnt Signaling on the Differentiation of Islet $\beta$-Cells From Adipose-Derived Stem Cells. BioMed Res Int (2017) 2017:2501578. doi: 10.1155/2017/2501578

140. Yang RH, Qi SH, Ruan SB, Lin ZP, Lin Y, Zhang FG, et al. EGFL7Overexpressing Epidermal Stem Cells Promotes Fibroblast Proliferation and Migration via Mediating Cell Adhesion and Strengthening Cytoskeleton. Mol Cell Biochem (2016) 423:1-8. doi: 10.1007/s11010-0162812-0

141. Nourian Dehkordi A, Mirahmadi Babaheydari F, Chehelgerdi M, Raeisi Dehkordi S. Skin Tissue Engineering: Wound Healing Based on Stem-CellBased Therapeutic Strategies. Stem Cell Res Ther (2019) 10:111. doi: 10.1186/ s13287-019-1212-2

142. Khatri R, Mazurek S, Petry SF, Linn T. Mesenchymal Stem Cells Promote Pancreatic $\beta$-Cell Regeneration Through Downregulation of FoxO1 Pathway. Stem Cell Res Ther (2020) 11:497. doi: 10.1186/s13287-020-02007-9

143. Mahdipour E, Salmasi Z, Sabeti N. Potential of Stem Cell-Derived Exosomes to Regenerate $\beta$ Islets Through Pdx-1 Dependent Mechanism in a Rat Model of Type 1 Diabetes. J Cell Physiol (2019) 234:20310-21. doi: 10.1002/jcp.28631

144. Conrad E, Stein R, Hunter CS. Revealing Transcription Factors During Human Pancreatic $\beta$ Cell Development. Trends Endocrinol Metab (2014) 25:407-14. doi: 10.1016/j.tem.2014.03.013

145. Zhou Q, Brown J, Kanarek A, Rajagopal J, Melton DA. In Vivo Reprogramming of Adult Pancreatic Exocrine Cells to Beta-Cells. Nature (2008) 455:627-32. doi: 10.1038/nature07314

146. Rhee M, Lee SH, Kim JW, Ham DS, Park HS, Yang HK, et al. Preadipocyte Factor 1 Induces Pancreatic Ductal Cell Differentiation Into InsulinProducing Cells. Sci Rep (2016) 6:23960. doi: 10.1038/srep23960
147. Chakravarthy H, Gu X, Enge M, Dai X, Wang Y, Damond N, et al. Converting Adult Pancreatic Islet $\alpha$ Cells Into $\beta$ Cells by Targeting Both Dnmt1 and Arx. Cell Metab (2017) 25:622-34. doi: 10.1016/ j.cmet.2017.01.009

148. Ribeiro D, Andersson E-M, Heath N, Persson-kry A, Collins R, Hicks R, et al. Human Pancreatic Islet-Derived Extracellular Vesicles Modulate Insulin Expression in 3D-Differentiating iPSC Clusters. PloS One (2017) 12: e0187665. doi: 10.1371/journal.pone.0187665

149. Oh JE, Choi OK, Park HS, Jung HS, Ryu SJ, Lee YD, et al. Direct Differentiation of Bone Marrow Mononucleated Cells Into Insulin Producing Cells Using Pancreatic $\beta$-Cell-Derived Components. Sci Rep (2019) 9:5343. doi: 10.1038/s41598-019-41823-9

150. Elmore S. Apoptosis: A Review of Programmed Cell Death. Toxicol Pathol (2007) 35:495-516. doi: 10.1080/01926230701320337

151. Chen Y, Hua Y, Li X, Arslan IM, Zhang W, Meng G. Distinct Types of Cell Death and the Implication in Diabetic Cardiomyopathy. Front Pharmacol (2020) 11:42. doi: 10.3389/fphar.2020.00042

152. de Souza BM, Bouças AP, Oliveira FD, Reis KP, Ziegelmann P, Bauer AC, et al. Effect of Co-Culture of Mesenchymal Stem/Stromal Cells With Pancreatic Islets on Viability and Function Outcomes: A Systematic Review and Meta-Analysis. Islets (2017) 9:30-42. doi: 10.1080/ 19382014.2017.1286434

153. Arzouni AA, Vargas-Seymour A, Rackham CL, Dhadda P, Huang GC, Choudhary P, et al. Mesenchymal Stromal Cells Improve Human Islet Function Through Released Products and Extracellular Matrix. Clin Sci (Lond) (2017) 131:2835-45. doi: 10.1042/CS20171251

154. Li X, Lang H, Li B, Zhang C, Sun N, Lin J, et al. Change in Viability and Function of Pancreatic Islets After Coculture With Mesenchymal Stromal Cells: A Systemic Review and Meta-Analysis. J Diabetes Res (2020) 2020:5860417. doi: 10.1155/2020/5860417

155. Zhao K, Hao H, Liu J, Tong C, Cheng Y, Xie Z, et al. Bone Marrow-Derived Mesenchymal Stem Cells Ameliorate Chronic High Glucose-Induced $\beta$-Cell Injury Through Modulation of Autophagy. Cell Death Dis (2015) 6:e1885. doi: 10.1038/cddis.2015.230

156. Keshtkar S, Kaviani M, Sarvestani FS, Ghahremani MH, Aghdaei MH, AlAbdullah IH, et al. Exosomes Derived From Human Mesenchymal Stem Cells Preserve Mouse Islet Survival and Insulin Secretion Function. Excli J (2020) 19:1064-80. doi: 10.17179/excli2020-2451

157. Chen J, Chen J, Cheng Y, Fu Y, Zhao H, Tang M, et al. Mesenchymal Stem Cell-Derived Exosomes Protect Beta Cells Against Hypoxia-Induced Apoptosis via miR-21 by Alleviating ER Stress and Inhibiting P38 MAPK Phosphorylation. Stem Cell Res Ther (2020) 11:97. doi: 10.1186/s13287-02001610-0

158. Sun Y, Shi H, Yin S, Ji C, Zhang X, Zhang B, et al. Human Mesenchymal Stem Cell Derived Exosomes Alleviate Type 2 Diabetes Mellitus by Reversing Peripheral Insulin Resistance and Relieving $\beta$-Cell Destruction. ACS Nano (2018) 12:7613-28. doi: 10.1021/acsnano.7b07643

159. Luo JZQ, Xiong F, Al-Homsi AS, Roy T, Luo LG. Human BM Stem Cells Initiate Angiogenesis in Human Islets In Vitro. Bone Marrow Transplant (2011) 46:1128-37. doi: 10.1038/bmt.2010.278

160. Sun Y, Mao Q, Shen C, Wang C, Jia W. Exosomes From $\beta$-Cells Alleviated Hyperglycemia and Enhanced Angiogenesis in Islets of StreptozotocinInduced Diabetic Mice. Diabetes Metab Syndr Obes (2019) 12:2053-64. doi: 10.2147/DMSO.S213400

161. Cantaluppi V, Biancone L, Figliolini F, Beltramo S, Medica D, Deregibus MC, et al. Microvesicles Derived From Endothelial Progenitor Cells Enhance Neoangiogenesis of Human Pancreatic Islets. Cell Transplant (2012) 21:1305-20. doi: 10.3727/096368911X627534

162. Nie W, Ma X, Yang C, Chen Z, Rong P, Wu M, et al. Human MesenchymalStem-Cells-Derived Exosomes are Important in Enhancing Porcine Islet Resistance to Hypoxia. Xenotransplantation (2018) 25:e12405. doi: 10.1111/ xen. 12405

163. Muthyala S, Safley S, Gordan K, Barber G, Weber C, Sambanis A. The Effect of Hypoxia on Free and Encapsulated Adult Porcine Islets-an In Vitro Study. Xenotransplantation (2017) 24:e12275. doi: 10.1111/xen.12275

164. Gesmundo I, Pardini B, Gargantini E, Gamba G, Birolo G, Fanciulli A, et al. Adipocyte-Derived Extracellular Vesicles Regulate Survival and Function of Pancreatic Beta Cells. JCI Insight (2021) 6:e141962. doi: 10.1172/jci.insight.141962 
165. Mattke J, Vasu S, Darden CM, Kumano K, Lawrence MC, Naziruddin B. Role of Exosomes in Islet Transplantation. Front Endocrinol (2021) 12:681600. doi: $10.3389 /$ fendo.2021.681600

166. Mayhew CN, Wells JM. Converting Human Pluripotent Stem Cells Into Beta-Cells: Recent Advances and Future Challenges. Curr Opin Organ Transplant (2010) 15:54-60. doi: 10.1097/MOT.0b013e3283337e1c

167. Russ HA, Parent AV, Ringler JJ, Hennings TG, Nair GG, Shveygert M, et al. Controlled Induction of Human Pancreatic Progenitors Produces Functional Beta-Like Cells In Vitro. EMBO J (2015) 34:1759-72. doi: 10.15252/ embj.201591058

168. Yabe SG, Fukuda S, Takeda F, Nashiro K, Shimoda M, Okochi H. Efficient Generation of Functional Pancreatic $\beta$-Cells From Human Induced Pluripotent Stem Cells. J Diabetes (2017) 9:168-79. doi: 10.1111/1753-0407.12400

169. Pavathuparambil Abdul Manaph N, Sivanathan KN, Nitschke J, Zhou X-F, Coates PT, Drogemuller CJ. An Overview on Small Molecule-Induced Differentiation of Mesenchymal Stem Cells Into Beta Cells for Diabetic Therapy. Stem Cell Res Ther (2019) 10:293. doi: 10.1186/s13287-019-1396-5

170. Gabr MM, Zakaria MM, Refaie AF, Abdel-Rahman EA, Reda AM, Ali SS, et al. From Human Mesenchymal Stem Cells to Insulin-Producing Cells: Comparison Between Bone Marrow- and Adipose Tissue-Derived Cells. BioMed Res Int (2017) 2017:3854232. doi: 10.1155/2017/3854232

171. Liu X, Qin J, Chang M, Wang S, Li Y, Pei X, et al. Enhanced Differentiation of Human Pluripotent Stem Cells Into Pancreatic Endocrine Cells in 3D Culture by Inhibition of Focal Adhesion Kinase. Stem Cell Res Ther (2020) 11:488. doi: 10.1186/s13287-020-02003-Z

172. Xu B, Fan D, Zhao Y, Li J, Wang Z, Wang J, et al. Three-Dimensional Culture Promotes the Differentiation of Human Dental Pulp Mesenchymal Stem Cells Into Insulin-Producing Cells for Improving the Diabetes Therapy. Front Pharmacol (2020) 10:1576. doi: 10.3389/fphar.2019.01576

173. Wang X, Ye K. Three-Dimensional Differentiation of Embryonic Stem Cells Into Islet-Like Insulin-Producing Clusters. Tissue Eng Part A (2009) 15:1941-52. doi: 10.1089/ten.tea.2008.0181

174. Nassar W, El-Ansary M, Sabry D, Mostafa MA, Fayad T, Kotb E, et al. Umbilical Cord Mesenchymal Stem Cells Derived Extracellular Vesicles can
Safely Ameliorate the Progression of Chronic Kidney Diseases. Biomater Res (2016) 20:21. doi: 10.1186/s40824-016-0068-0

175. Liu A, Zhang X, He H, Zhou L, Naito Y, Sugita S, et al. Therapeutic Potential of Mesenchymal Stem/Stromal Cell-Derived Secretome and Vesicles for Lung Injury and Disease. Expert Opin Biol Ther (2020) 20:125-40. doi: 10.1080/14712598.2020.1689954

176. Sengupta V, Sengupta S, Lazo A, Woods P, Nolan A, Bremer N. Exosomes Derived From Bone Marrow Mesenchymal Stem Cells as Treatment for Severe COVID-19. Stem Cells Dev (2020) 29:747-54. doi: 10.1089/ scd. 2020.0080

177. Jayaramayya K, Mahalaxmi I, Subramaniam MD, Raj N, Dayem AA, Lim $\mathrm{KM}$, et al. Immunomodulatory Effect of Mesenchymal Stem Cells and Mesenchymal Stem-Cell-Derived Exosomes for COVID-19 Treatment. BMB Rep (2020) 53:400-12. doi: 10.5483/BMBRep.2020.53.8.121

Conflict of Interest: YZ is an inventor for Stem Cell Educator therapy and has a fiduciary role at Throne Biotechnologies.

The remaining authors declare that the research was conducted in the absence of any commercial or financial relationships that could be construed as a potential conflict of interest.

Publisher's Note: All claims expressed in this article are solely those of the authors and do not necessarily represent those of their affiliated organizations, or those of the publisher, the editors and the reviewers. Any product that may be evaluated in this article, or claim that may be made by its manufacturer, is not guaranteed or endorsed by the publisher.

Copyright (C) $2022 \mathrm{Hu}$, Song, Yu, Sun, Wang and Zhao. This is an open-access article distributed under the terms of the Creative Commons Attribution License (CC BY). The use, distribution or reproduction in other forums is permitted, provided the original author(s) and the copyright owner(s) are credited and that the original publication in this journal is cited, in accordance with accepted academic practice. No use, distribution or reproduction is permitted which does not comply with these terms. 